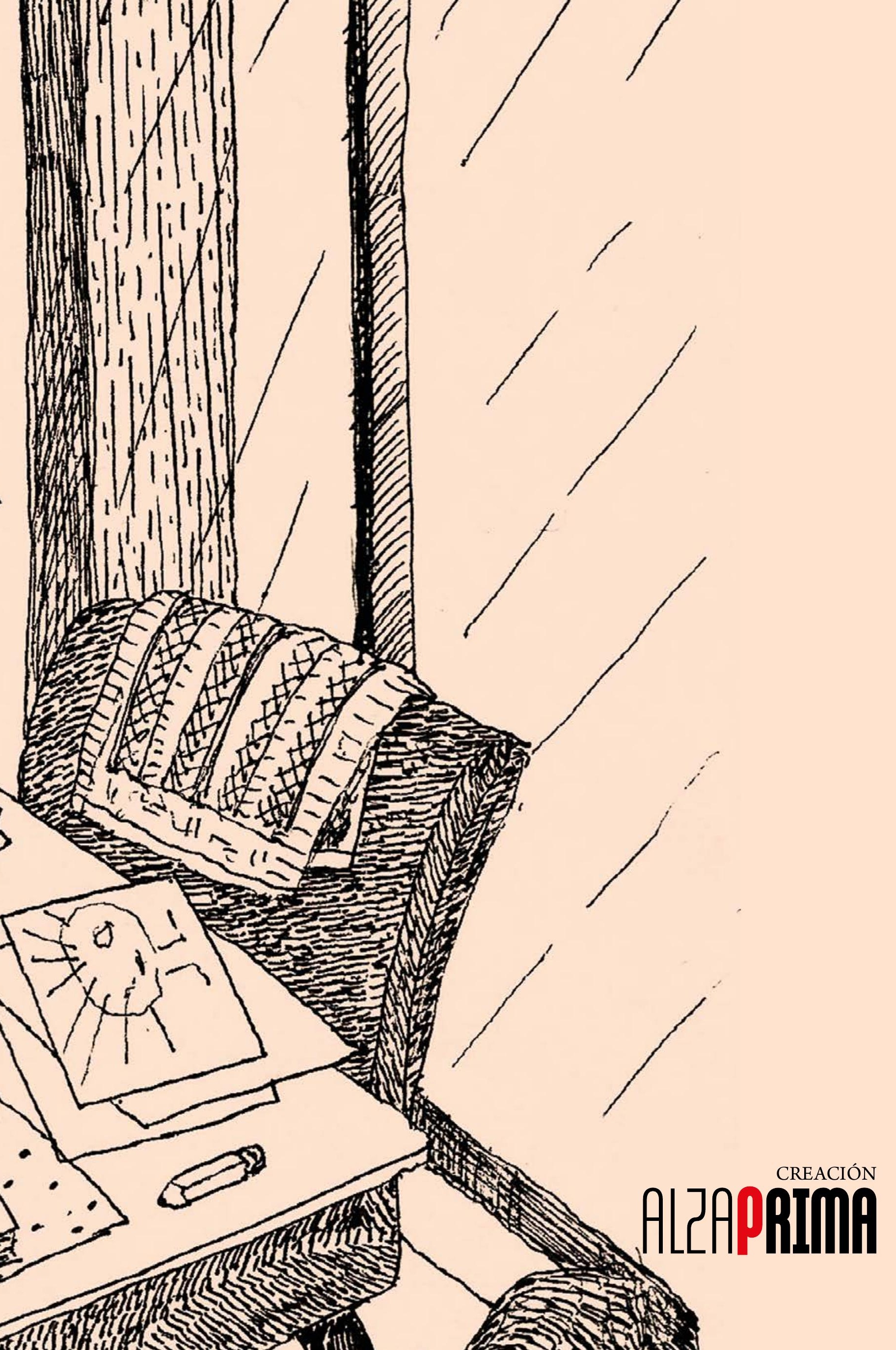




\section{NUEVA LAS CONDES: ¿PARA TODOS? ¿NO HAY RAZAS? ¿TODOS JUNTOS?} NEW LAS CONDES: FOR ALL? NO RACES? ALL TOGETHER?

Valentina Utz Wirnsberger (Chile)

Artista Visual, Master of Arts, Art in Context, mención Espacio Público y Arte con Grupos

Humanos, Universidad de las Artes de Berlín.

www.valentinautz.com

https://doi.org/10.29393/AP13-6NCVU10006

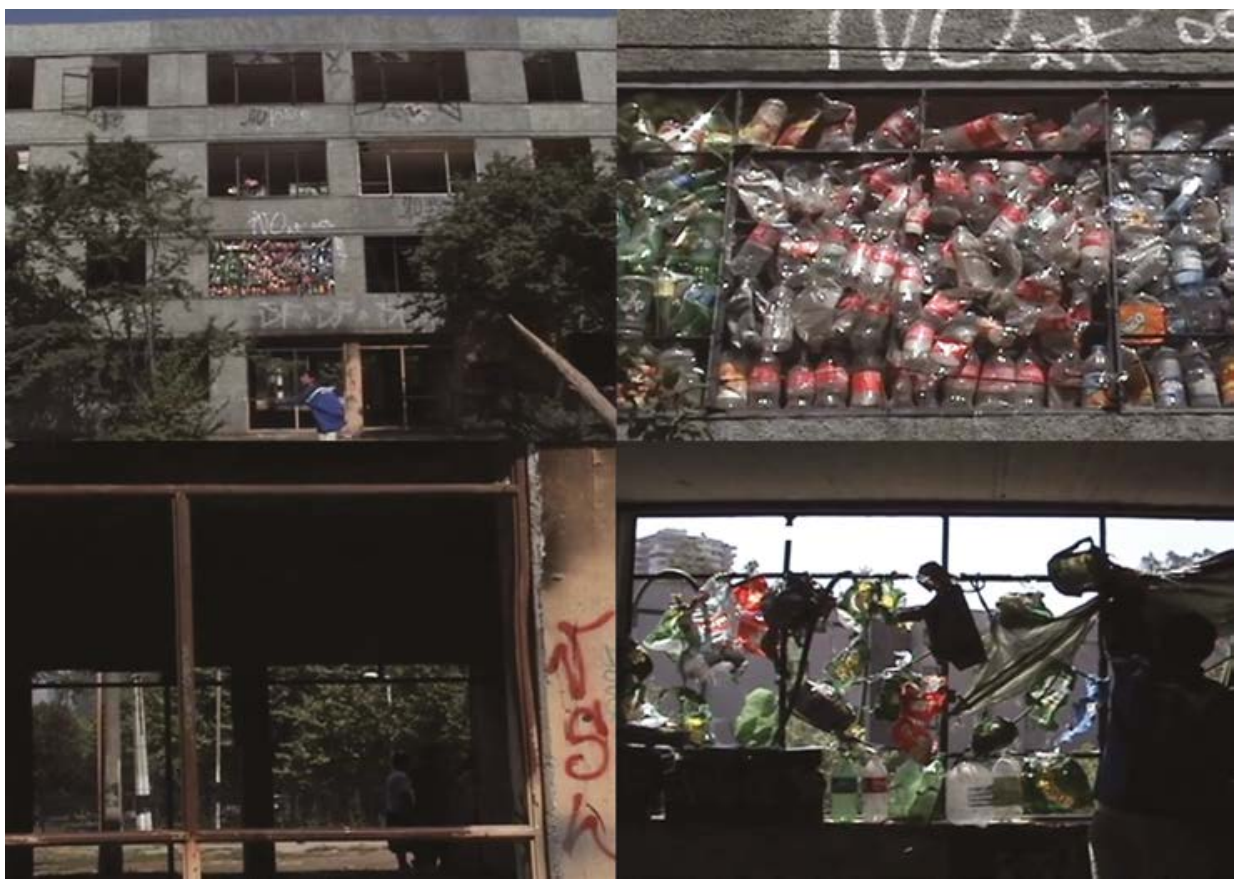

Fig. ${ }^{\circ}$ 1: Acción urbana en Villa San Luis, 2009, Santiago, Chile. Fotomontaje a partir de frame de video, formato 4:3, 6.07 min. Cámara: Mathias Klenner. Edición: Valentina Utz. 
En mis investigaciones me han interesado los espacios intersticiales de las ciudades, especialmente allí donde la organización urbana privilegia la expansión de proyectos privados que transgreden el bien común, dislocando los lugares del entorno. Las dos obras aquí presentadas son acciones performáticas relacionadas con la Villa San Luis (Las Condes, Santiago de Chile) entre los años 2009 y 2017. El foco urbano de las intervenciones corresponde a la ex Villa Compañero Ministro Carlos Cortés, construida en 1972 por la Corporación de Mejoramiento Urbano (CORMU), con el propósito de acercar a las personas a sus lugares de trabajo y así evitar la desigualdad y los largos tiempos de desplazamiento entre comunas distantes (no sólo en kilómetros).

Las ruinas de la Villa San Luis, nos recuerdan las políticas urbanas en periodos previos a la dictadura cívico militar de 1973, y fueron declaradas Monumento Histórico por el Consejo de Monumentos Nacionales, en el año 2017.

Recién el año 2009, conocí la presencia de los dos edificios sociales abandonados de la Villa San Luis y me pregunto ¿cómo se había desplomado el sueño de la vivienda social? El año 1976, en plena dictadura, ocurre el violento desalojo de la población, realizado de manera aberrante por camiones de basura. Los departamentos pasaron a estar en manos de militares y luego de las inmobiliarias, iniciándose su progresiva demolición, según las familias que quedaban y aquellas que accedían a vender. En 1997, el alcalde Joaquín Lavín posaba sobre una retroexcavadora ante la difícil destrucción de los sólidos bloques: una más de las tristes paradojas de las decisiones urbanas en ciudades sísmicas. 
La primera acción Villa San Luis la realicé el año 2009 al interior de uno de los edificios que quedaban erguidos, pero deshabitados, mientras en los departamentos posteriores se observaba el devenir cotidiano de sus habitantes. En la intervención reúno y clasifico en las ventanas los desechos encontrados en el mismo espacio, donde se reconocen las diferencias cromáticas y matéricas, como también mi cuerpo y el de uno de los habitantes que apoyó la construcción efímera. El demarcar el lugar de forma particular era un modo de significar y dar un valor diferencial, al menos visual, a estas ruinas históricas. En el registro audiovisual ${ }^{1}$ se muestran momentos intermedios entre el inicio y el final de mis acciones, dando cuenta de distintas etapas del proceso y de la transformación de las formas o del cuerpo.

En la segunda acción, Desde el Parque Arauco a la Villa San $\mathrm{Luis}^{2}$, se evocó la transformación del barrio Nueva Las Condes, recordando un pasado al remarcar la situación del lugar. Seleccioné 15 enunciados de publicidad del centro comercial, que se contradicen con el cambio urbano neoliberal, por ejemplo: "Para todos", "No hay razas", "Todos juntos", para repetirlas y reconstruir "la trayectoria invisible que conecta el paisaje publicitario del mall con las estructuras devastadas del último lote. En la ciega fatalidad de un camino hecho en reversa, resuena la promesa trunca de la ciudad socialista que no terminó de materializarse." (Pinochet Cobos, 2019, p. 42)

Fig. n², 3, 4, 5: Acción urbana en Villa San Luis, 2009, Santiago, Chile. Fotomontaje a partir de frame de video, formato 4:3, $6.07 \mathrm{~min}$. Cámara: Mathias Klenner. Edición: Valentina Utz.

Fig. n6, 7, 8: Acción urbana Desde Parque Arauco a la Villa San Luis, 2017, Santiago, Chile. Fotomontaje a partir de frame de video, formato 4:3, $4.55 \mathrm{~min}$. Cámara: Mathias Klenner y Fernanda Fábrega. Edición: Valentina Utz. Colaboración Grupo TOMA.

1. Video Villa San Luis : https://vimeo.com/78417211

2. Video Desde el Parque Arauco a la Villa San Luis : https://youtu.be/cQ4-yb4nRDA 


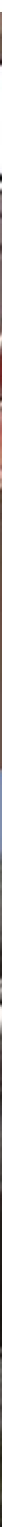

Fig. no2 

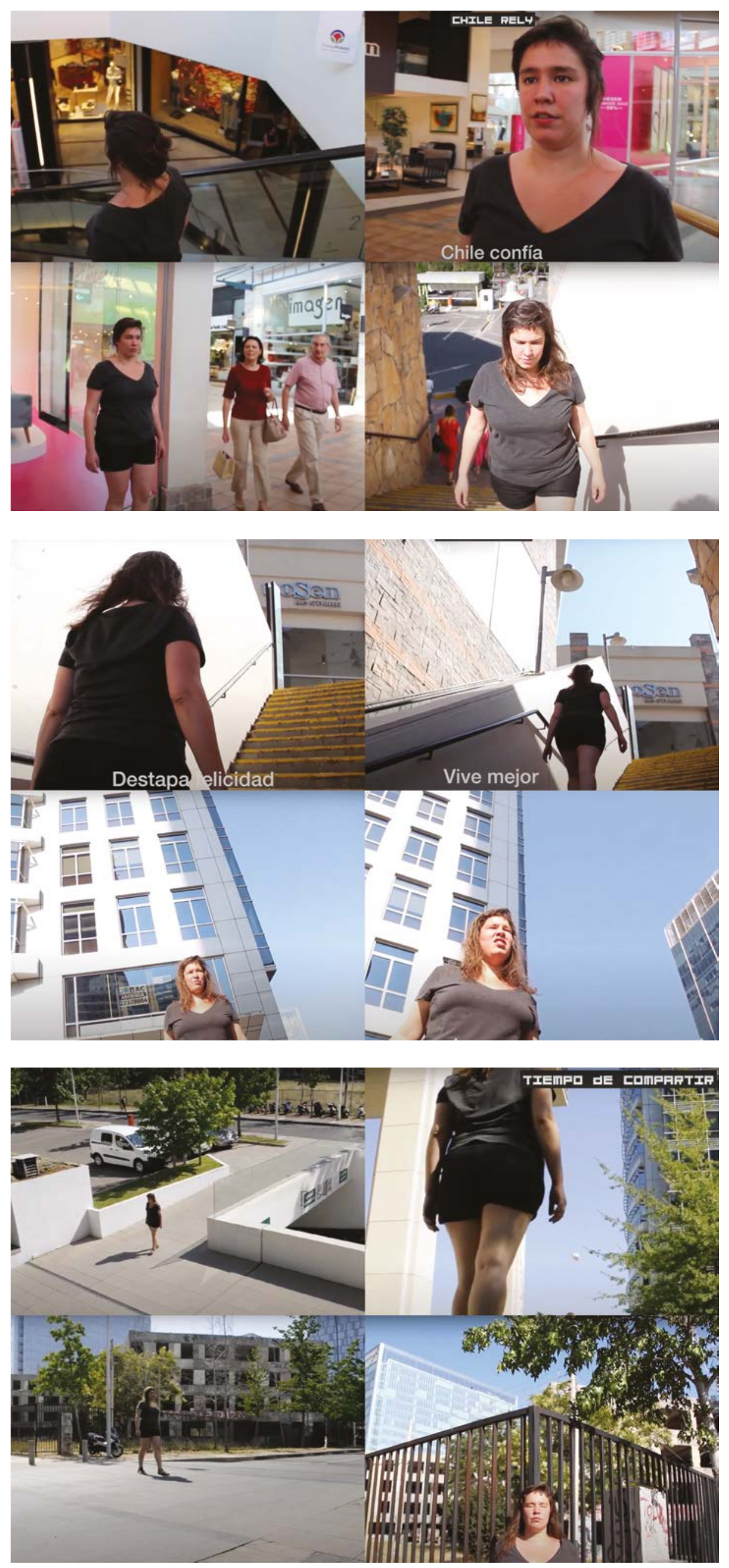